\title{
Reconhecendo Analogias e Precedentes a Partir de Decisóes da Justiça do Trabalho: Dois Esquemas de ARgumentação Caso a Caso
}

\author{
Recognizing Analogies and Precedents in \\ Labor Court Decisions: Two Case-To-case \\ Argumentation Schemes
}

\section{Reconocimiento de Analogías y PRecedentes a Partir de Decisiones de la Justicia del Trabajo: Dos Esquemas de Argumentación Caso a Caso}

\author{
Mário Cesar da Silva Andrade* \\ Daniel de Souza Lucas * *
}

\begin{abstract}
1 Introdução. 2 Qual é a lógica do argumento por analogia?. 2.1 Identificando semelhanças relevantes: as analogias intuitivas. 2.2 Identificando semelhanças relevantes e consistentes: alguns esquemas possíveis. 2.3 Tratando casos semelhantes da mesma maneira: os argumentos analógicos no direito. 3 Qual é a lógica do argumento por precedente?. 3.1 Tratando casos semelhantes (coercitivamente) da mesma forma: o uso de precedentes no direito. 4 Conclusão. Referências.
\end{abstract}

\section{RESUMO}

O presente artigo destaca as diferenças entre a argumentação que apela ao precedente para decidir e aquela que justifica a decisão tendo por base uma analogia. Compreender as diferenças é relevante, pois é a partir da argumentação que as instâncias superiores uniformizam os entendimentos que serão percebidos como vinculantes pelas instâncias inferiores. Meto-

* Professor da Universidade Federal de Juiz de Fora/MG (UFJF). Doutorando em Teorias Jurídicas Contemporâneas na Faculdade Nacional de Direito da Universidade Federal do Rio de Janeiro (FND/UFRJ). Mestre em Direito e Inovação pela Universidade Federal de Juiz de Fora (UFJF). Pesquisador do Observatório da Justiça Brasileira (OJB/UFRJ). E-mail: <cesarandrade.mario@ufjf.edu.br>. http://orcid.org/0000-0001$7277-8274$

** Mestrando em Teorias Jurídicas Contemporâneas no Programa de Pós-graduação em Direito da Faculdade Nacional de Direito da Universidade Federal do Rio de Janeiro (UFRJ). Pesquisador. E-mail: <dsldireito@ gmail.com >. http://orcid.org/0000-0003-4690-2336 
dologicamente, a pesquisa qualitativa bibliográfica utiliza as contribuições teóricas no tema, em especial, as de Katharina Stevens e Trudy Govier, para, de forma hipotético-dedutiva, reconstruir argumentos judiciais que problematizam os efeitos do precedente e da analogia no direito. A pesquisa vale-se de fontes doutrinárias, legislativas e jurisprudenciais. Em conclusão, a aceitação da tese de que existem duas versões do princípio de acordo com o qual casos semelhantes devem ser tratados igualmente permite diferenciar objetivamente os casos de analogia e os de precedente. As estruturas e as perguntas críticas propostas por Stevens conseguem dar suporte à avaliação do contexto e da intenção do autor do argumento, o que é fundamental para perceber uma decisão anterior como vinculante.

Palavras-chave: Analogia. Precedente. Argumentação caso a caso.

\begin{abstract}
The present article highlights the differences between argumentation schemes that appeal to the precedent in order to take a decision and other schemes that justify their decision based on analogies. Understanding the differences between these two types of schemes is relevant, because it is through argumentation that the higher courts can standardize the understandings that will be perceived as binding by the inferior courts. Methodologically, the qualitative bibliographical research uses theoretical contributions to the topic, especially the ones by Katharina Stevens and Trudy Govier, so that we can rebuild in a hypothetical-deductive way judicial arguments that problematize the effects of the precedent and analogy in law. The research uses doctrinaire, legislative and jurisprudential sources. In conclusion, the acceptance of the thesis that there are two versions of the agreement principle of treating similar cases equally allows us to differentiate objectively between cases of analogy and those of precedent. The structures and critical questions proposed by Stevens can support the evaluation of the context and intention of the argument's author, which is fundamental to perceive a previous decision as binding.
\end{abstract}

Keywords: Analogy. Precedent. Case-to-case Argumentation.

\title{
RESUMEN
}

El presente artículo resalta las diferencias entre la argumentación que recurre al precedente para decidir y aquella que justifica la decisión basada en una analogía. Comprender las diferencias es relevante, porque es a partir de la argumentación que las instancias superiores uniformizan los entendimientos que serán percibidos como vinculantes por las instancias inferiores. Metodológicamente, la investigación bibliográfica cualitativa utiliza las contribuciones teóricas en el tema, en especial las de Katharina Stevens y Trudy Govier, para, de forma hipotéticodeductiva, reconstruir argumentos judiciales que problematizan los efectos del precedente 
y de la analogía en el derecho. La investigación utiliza fuentes doctrinarias, legislativas y jurisprudenciales. En conclusión, la aceptación de la tesis de que hay dos versiones del principio de acuerdo con el cual casos similares deben ser tratados igualmente permite diferenciar objetivamente entre casos de analogía y los de precedente. Las estructuras y preguntas críticas propuestas por Stevens pueden apoyar la evaluación del contexto y de la intención del autor del argumento, lo que es fundamental para percibir una decisión previa como vinculante.

Palabras clave: Analogía. Precedente. Argumentación caso a caso.

\section{INTRODUÇÃO}

A função das instâncias superiores é atribuir sentido ao direito e contribuir para sua evolução, mediante decisões que não podem deixar de ter força obrigatória. Pelo menos, é nesse sentido que a doutrina brasileira do precedente se manifesta (MARINONI, 2016, p. 105). Porém, qual é sua lógica? Para colaborar com o esclarecimento dessa questão, parte-se do pressuposto de que o novo Código de Processo Civil (CPC/2015) permitiu o estabelecimento de um sistema em que precedentes são considerados como vinculantes. Isso demanda uma reflexão sobre como essa vinculação opera a partir de duas lógicas que, apesar de distintas, estão intrinsicamente ligadas: a do precedente e a da analogia. Busca-se analisar mais detidamente tais raciocínios, a fim de desfazer confusões conceituais, além de ofertar um instrumental para aumentar a consistência teórica da utilização judicial de decisões passadas na fundamentação da resolução de casos presentes.

O raciocínio por analogia é central na cognição humana, além de ser um componente-chave da tomada de decisão especializada e profissional. Talvez, por isso seja intuitivo pensar que o uso de precedentes é a formalização do raciocínio analógico ou o motivo pelo qual advogados e juízes estudam analogia (SCHAUER, 2008, p. 1-2). Contudo, isso deve conduzir à conclusão de que raciocinar por precedentes é raciocinar por analogia?

Lamond (2016) entende que não, haja vista que o simples fato de existir uma decisão em determinado sentido não estabelece a presunção de que se deva decidir da mesma forma no futuro. Ele reconhece que é a existência de circunstâncias especiais que induzem tal feito. De maneira que, na ausência de tais circunstâncias, é sempre possível reconsiderar a decisão anterior quando se entende que o julgamento original estava incorreto.

Se seguir um precedente é ter a obrigação de considerar uma decisão anterior apenas em razão de sua existência, e não de seu mérito, o que Schauer (2008, p. 2-3) considera contra intuitivo; e realizar uma analogia é aprender com um caso passado para alcançar a melhor decisão possível no caso atual (SCHAUER, 2009, p. 39), quais são os esquemas abstratos ${ }^{1}$ que melhor evidenciam as características desses dois tipos de tomada de decisão?

1 Esquemas abstratos são representações dos diferentes tipos de argumentos em que se destaca o aspecto geral das suas partes essenciais: as premissas e a conclusão. 
Para responder à pergunta, este artigo parte da discussão teórica sobre esquemas argumentativos analógicos para assim problematizar os possíveis efeitos prospectivos de uma analogia no direito. Isso é útil à medida que permite comparar a analogia feita nesses termos à estrutura do argumento por precedente. A partir disso, é desenvolvida uma crítica aos efeitos prospectivos atribuídos ao precedente na doutrina majoritária brasileira, a qual tem pretendido justificar o uso dos precedentes a partir do princípio geral de acordo com o qual casos semelhantes devem ser tratados igualmente (treating like cases alike).

Partindo, destacadamente, das contribuições teóricas de Katharina Stevens, Trudy Govier e Frederick Schauer para a investigação científica de decisões alegadamente baseadas nos precedentes e no uso de analogia no processo decisório judicial, a presente pesquisa adota o método hipotético-dedutivo, buscando analisar as formulações extraídas da teoria dos precedentes e do raciocínio por analogia, além de confrontá-las, criticamente, com a prática jurisprudencial brasileira dominante nos tribunais superiores, a fim de analisar as contribuições dos estudos analíticos sobre decisões por analogia para a prática decisória por precedentes. Nesse sentido, a pesquisa qualitativa bibliográfica-documental vale-se de fontes doutrinárias, legislativas e jurisprudenciais, com destaque para a análise de decisões de tribunais superiores.

O artigo está dividido em duas seções. A primeira seção trata da lógica da analogia, apresentando os esquemas elaborados na tentativa de identificar premissas universais em seus argumentos analógicos, seus fundamentos e suas consequências. Em particular, busca-se analisar o papel da analogia no raciocínio em geral e suas repercussões no ambiente fortemente institucionalizado do direito, em que, muitas vezes, ganha a aparência de precedente. Na segunda seção, é apresentada a lógica do precedente e sua principal diferença em relação à lógica da analogia. A partir do esquema abstrato proposto e do conjunto de perguntas críticas auxiliares, busca-se, em particular, reconstruir e avaliar argumentos reais em que a decisão de um tribunal foi constrangida por decisão anterior, considerada como precedente, para demonstrar que a presença de razões de segunda ordem é fundamental para diferenciar um e outro tipo de tomada de decisão.

\section{QUAL É A LÓGICA DO ARGUMENTO POR ANALOGIA?}

Enquanto argumento, a analogia pode ser de dois tipos: (i) a priori, também chamada de hipotética, ou (ii) indutiva. A principal característica do raciocínio analógico é a possibilidade de estabelecer uma conclusão sobre um caso-alvo com base na comparação com um caso-fonte, em função de algum aspecto relevante ou similar. ${ }^{2}$ As analogias do segundo tipo chegam a uma generalização que pretende predizer semelhanças possíveis em função de similaridades observadas indutivamente na comparação (GOVIER, 1989, p. 141). Devido ao seu caráter empírico, esse tipo de analogia não é o foco deste artigo.

2 Cf. Schauer (2009, p. 85-87), quando alguém realiza uma analogia está destacando que alguma característica do caso-fonte está presente no caso-alvo, e, consequentemente, que o que se pode dizer do caso-fonte também se pode dizer do caso-alvo. 
Para avançar na distinção entre analogias e precedentes, é particularmente importante o primeiro tipo de analogia, porque, a partir dela, aspectos relevantes são construidos para mostrar que a decisão no caso-alvo está correta em função da decisão no caso-fonte (GOVIER, 1989, p. 142). De maneira mais precisa, uma analogia a priori usa um caso relativamente fácil de entender e suficientemente incontroverso para clarificar ou esclarecer um caso controverso. Isso é feito apelando-se às semelhanças que o autor da analogia julga mais importantes. Para Govier (2013, p. 319), esse raciocínio é um aspecto fundamental da racionalidade em geral.

\subsection{IDENTIFICANDO SEMELHANÇAS RELEVANTES: AS ANALOGIAS INTUITIVAS}

É comum que, na lógica, na moral ou no direito, o uso de analogias envolva a aplicação de um princípio ou regra geral de consistência, que torne possível, ao longo do tempo, selecionar quais casos são relevantemente semelhantes a ponto de merecerem tratamento similar (GOVIER, 2013, p. 320). Um dos esquemas usados para justificar o tratamento nos mesmos termos, podendo ser talvez o mais comum, é o esquema da analogia intuitiva. De acordo com esse esquema,

(Esquema 1)

1. Se A deve ser tratado como Z; e

2. B é como se fosse A;

Então,

3. B deve ser tratado como Z.

Confira um exemplo real que parece encaixar-se nesse tipo de esquema. A Justiça do Trabalho do Estado do Paraná precisava decidir se uma técnica administrativa do setor de cobrança de uma grande fabricante de cerveja, cuja principal atividade era atender e realizar chamadas telefônicas (ela negociava com clientes), poderia ter sua jornada de trabalho reduzida de oito para seis horas diárias contínuas, ou de quarenta e quatro para trinta e seis horas semanais. A técnica alegava que exercia a função de telefonista e, portanto, merecia a proteção garantida pelo art. 227 da Consolidação das Leis Trabalhistas (CLT). A decisão da primeira instância concluiu que:

Ao contrário do asseverado em defesa, a prova oral produzida revelou que o telefone era o principal instrumento de trabalho utilizado pela Autora. A utilização do head fone alegada na inicial não foi alvo de impugnação específica pela Ré, presumindo-se a sua veracidade, a teor do art. 302, CPC. O preposto da Ré, em seu depoimento, confirma o elevado número de ligações diárias realizadas e recebidas pela Autora, podendo chegar ao total de 120 (fl. 324 - item 14). A testemunha arrolada pela Ré confirma que a atividade preponderante era atender ligações telefônicas e realizá-las (fl. 325 - item 10). Incide, por analogia, o disposto no artigo 227, CLT. Para preservar a mens legis e, por consequência, os fins sociais a que se destina a norma referida [...] (BRASIL, 2014, p. 13). 
Usando o Esquema 1, essa decisão monocrática determina que duas categorias distintas (telefonista e técnico administrativo o qual usa muito o telefone) merecem o mesmo tratamento jurídico pode ser reconstruída da seguinte forma:

(Argumento 1)

1. Quem cumpre a função de operador de serviço de telefonia deve, de acordo com o art. 227 da CLT, ter carga horária reduzida (BRASIL, 1943);

2. O técnico administrativo que realiza muitas ligações telefônicas é como se fosse um operador de serviço de telefonia;

Logo,

3. O técnico administrativo que realiza muitas ligações telefônicas deve ter carga horária reduzida.

Qual o problema com o uso desse tipo de esquema? Como ele não aponta o que foi considerado como semelhança relevante entre os casos, os futuros autores que recorrerem a essa decisão como fonte de uma analogia poderão extrair com liberdade, recorrendo à intuição, o critério de semelhança entre os casos. Analogias desse tipo são conhecidas como analogias intuitivas ou não-especificas. ${ }^{3}$

Por exemplo, o fim social da norma, que justifica a redução da carga de trabalho, é proteger do desgaste físico e mental quem passa muito tempo ao telefone? Intuitivamente, a resposta pode até ser positiva, mas críticas podem ser suscitadas. $O$ fato de telefonar ser a principal função da técnica administrativa e a única função de uma telefonista dificilmente poderia ser a justificativa para um tratamento, necessariamente, igual. As demais atividades da técnica administrativa podem desgastá-la ou preservá-la ainda mais, se comparadas à função de telefonista. A analogia da Justiça do Trabalho do Estado do Paraná não permite entender os parâmetros da comparação, comprometendo sua análise argumentativa e, consequentemente, seu controle. Nessa linha, ainda que exista a analogia alegada, a argumentação restará falaciosa, tendo em vista que o argumento deixou de indicar suas bases.

\subsection{IDENTIFICANDO SEMELHANÇAS RELEVANTES E CONSISTENTES: ALGUNS ESQUEMAS POSSÍVEIS}

E como funcionaria um esquema de argumento analógico a priori que consiga articular as similaridades relevantes entre os casos comparados e quaisquer outros casos? Como evitar o uso ad hoc da analogia, ou seja, como evitar um uso não comprometido com a consistência em um número maior de casos?

Tentando atribuir um caráter dedutivo às analogias que estabelecem decisões sobre o que fazer ou o que dizer, Govier $\left(1989\right.$, p. 143) parte da estrutura de um esquema indutivo, ${ }^{4}$

3 Forma de raciocínio analógico que conclui pela semelhança sem, no entanto, apontar quais características foram relevantes para a conclusão, Cf. Govier (1989, p. 143).

4 Cf. Govier (1989, p. 141), as analogias indutivas envolvem um esquema com uma premissa preditiva (a premissa 4 abaixo), isso difere substancialmente da pretensão envolvida nos casos de analogia $a$ priori. 
em que $A$ se refere ao caso-fonte, $B$ ao caso-alvo e as letras $x, y$, z refletem características específicas compartilhadas por A e B explicitamente, para articular um modelo que considere as semelhanças relevantes:

(Esquema 2)

1. A possui as características $\mathrm{x}, \mathrm{y}, \mathrm{z}$;

2. B possui as características $\mathrm{x}, \mathrm{y}, \mathrm{z}$;

3. A é W;

Então,

\section{B é W.}

Para ela, após formular um argumento nesses termos, o autor passa naturalmente a usar um esquema implicitamente dedutivo, extrapolando a consequência $W$ de modo que ela atinja qualquer proposição que compartilhe das mesmas características:

(Esquema 3)

\section{A possui as características $\mathrm{x}, \mathrm{y}, \mathrm{z}$;}

2. B possui as características $\mathrm{x}, \mathrm{y}, \mathrm{z}$;

3. A é W;

4. É em virtude de $x, y, z$, que A é W;

5. Todas as coisas que possuem as características $\mathrm{x}, \mathrm{y}, \mathrm{z}$ são $\mathrm{W} ;{ }^{6}$

Então,

6. B é W.

Govier (1989, p. 144) usa o esse esquema para explorar a ideia de que analogias com essa estrutura são argumentos implicitamente dedutivos, em função da premissa 4, em geral pressuposta, e da premissa 5, uma declaração universal. Nesses termos, a analogia pode ser conduzida a um nível de abstração em que a comparação entre casos torna-se desnecessária, por ser possível realizar um silogismo quase-lógico com a premissa 5.

Para ela, existem dois problemas nessa forma de representação dos argumentos analógicos a priori: (i) muitas vezes, o autor da analogia não pode indicar uma premissa universal adequada para tornar o argumento dedutivamente válido; e (ii) essa premissa universal, quando possível, pode ser contestada, uma vez que o autor da analogia usada como caso-fonte, efetivamente, nunca a estipulou (GOVIER, 1989, p. 144-145).

Essas objeções são importantes, principalmente a segunda, porque permitem entender as razões pelas quais argumentos analógicos não têm a capacidade de constranger o tomador
1. A tem as características $x, y, z$.
2. B tem as características $x, y, z$.
3. A tem a característica $\mathrm{f}$.
4. A maioria das coisas que possuem as características $x, y, z$, tem a característica f.
5. Portanto, provavelmente, B tem a característica f.

5 Segundo Govier (1989, p. 144), essa é uma afirmação que normalmente parece pressuposta por quem usa o argumento.

6 Essa seria uma declaração universal implícita, formulada por terceiro. 
de decisão no caso-alvo. Quando uma premissa como a (5) está explícita, não é necessário o recurso à analogia. Quando ela está implícita, sua extração não está livre de objeções. Em verdade, o autor da analogia no caso-alvo, que atribuiu ao autor da analogia no caso-fonte a estipulação de uma premissa como a (5), está sujeito à acusação de ter cometido uma falácia de recurso à autoridade, para dar verniz institucional a sua preferência pessoal.

As objeções de Govier mobilizaram pesquisadores como Bruce Waller, na tentativa de defender o caráter dedutivo da analogia. Para Waller (2001, p. 205-206), a premissa (5) seria um princípio subjacente essencial, "premissa universal”, nos termos de Govier, importante na resolução de casos difíceis. Ela seria a parte substantiva do argumento analógico a priori. Para ele, Govier não conseguiu negar a existência de um processo dedutivo no interior da analogia a priori, apenas contestou qual é a natureza dos princípios subjacentes (WALLER, 2001, p. 206).

Waller (2001, p. 206-207) estabeleceu uma relação entre a conclusão alcançada por Govier e sua posição no debate entre formalistas e realistas na teoria do direito. Formalistas caracterizam o raciocínio jurídico como operando a partir de precedentes que estabelecem princípios universais subjacentes fixos, a partir dos quais todas as disputas jurídicas podem ser resolvidas. Eles apelam ao raciocínio a partir de precedentes para encontrar verdades jurídicas eternas, cabendo ao juiz a única tarefa de descobrir essas verdades ocultas. Realistas rejeitam essa ideia e entendem que os princípios subjacentes são construções humanas, não verdades transcendentes.

Assim, ele reconhece que Govier tem razões para rejeitar a existência de uma premissa universal ou princípio subjacente fixo, completo e transcendente, mas insiste que, nem o universal (o princípio), nem os particulares (os casos semelhantes), devem ter status lógico ou epistêmico superior na estrutura da analogia a priori. Ele propôs entender a relação entre particular e universal como uma relação de ajuste mútuo, e não de hierarquia rígida (WALLER, 2001, p. 207).

Em tréplica, Govier (2002, p. 155) buscou identificar os termos do ajuste mútuo de Waller: (Esquema 4)

1. Nós dois concordamos com $a$;

2. A razão mais plausível para esse acordo é a aceitação da premissa universal C;

3. C implica $b$, em que $b$ é um caso que se encaixa no escopo do princípio $C$; Então,

4. A consistência requer a aceitação de $b$.

Seria possível aferir os termos de um consenso a partir de argumentos analógicos?

Govier (2002, p. 156) entendeu que não, porque, ao imputar à audiência, a saber, os posteriores autores de analogias ao longo do tempo, a tarefa de identificar o princípio C, Waller reconheceu que $\mathrm{C}$ não era parte integrante do argumento original. $\mathrm{O}$ ajuste mútuo que a analogia a priori permitiria alcançar seria um ajuste circunstancial decorrente da composição da audiência em determinado contexto. Ela considera incoerente a função atribuída 
aos argumentos analógicos a priori: lembrar um princípio que a audiência conscientemente aceita durante a troca argumentativa (SHECAIRA, 2013, p. 412). Se quem estabelece a premissa universal, o faz ajustando-a caso a caso, como ela pode ser universal??

Shecaira (2013, p. 409), em defesa de Waller, procura defender o caráter dedutivo das analogias a priori, oferecendo uma versão modificada do esquema argumentativo. Para ele, esse tipo de argumento é complexo e composto por duas inferências: uma não-dedutiva e outra dedutiva. De modo que o problema da premissa logicamente redundante (a premissa 5 do Esquema 3) poderia ser afastado.

(Esquema 5)

1. É verdade que $a$.

2. A melhor razão para a crença em $a$ é a premissa universal C.

Então,

3. É verdade que C (inferência não-dedutiva).

4. C implica $b$.

Logo,

5. É verdade que $b$ (inferência dedutiva).

Nesse esquema, o ajuste mútuo proposto por Waller (que envolveria buscar o que a audiência aceitaria conscientemente na troca argumentativa) assume o caráter de testagem retórica de uma premissa universal discreta formulada no caso-fonte, um subargumento não-dedutivo que se assemelha à inferência para a melhor explicação (SHECAIRA, 2013, p. 435). É assim que, para ele, os argumentos analógicos que dependem de princípios são melhores do que argumentos analógicos baseados nas chamadas analogias intuitivas. Ao não articular semelhanças relevantes entre análogos, as analogias intuitivas são capazes de alienar as pessoas que simplesmente não conseguem "enxergar" as semelhanças em questão (SHECAIRA, 2013, p. 435). ${ }^{8}$

7 A ideia do ajuste mútuo transcende a discussão acerca do caráter dedutivo das analogias. É possível vê-la, por exemplo, na forma como Lopes Filho (2012, p. 244- 245) defende que sejam tratados os precedentes. O círculo hermenêutico da aplicação do precedente é, em alguma medida, um processo analógico de ajuste caso a caso, razão pela qual a ideia do precedente vinculante fica prejudicada. O "precedente" que supre a lacuna da lei não é um "precedente", se sua aplicação está condicionada à concordância do tomador de decisão quanto às razões que foram dadas para crer que o resultado alcançado foi justo e correto. Essa característica distintiva na identificação da analogia fica em segundo plano, porque a concepção mais familiar ao direito brasileiro é aquela em que a analogia supre a lacuna da lei, tal qual um precedente. Mas é importante notar que o funcionamento do "precedente" nesses termos não deixa de ter a estrutura analógica e a finalidade de dar razões para crer.

8 A esta altura pode não ter ficado claro se é problemático ou não formular uma premissa universal não explicitamente enunciada no argumento original. Muitos intuiriam que é exatamente a premissa universal quem garante a extensão do raciocínio de um caso para o outro com base nas semelhanças e, consequentemente, a consistência das decisões. Porém, a premissa universal implícita é sempre um risco, haja vista sua contínua reformulação a cada uso. A única forma de mitigar o risco é crer que o autor da analogia será caridoso no momento dessa reformulação, o que é uma garantia fraca de que não haverá uso ad hoc da premissa universal. $\mathrm{O}$ problema da premissa universal não é seu efetivo uso pelo autor da analogia, mas sim a alegação por terceiros de que uma premissa universal formulada anteriormente gerou expectativas que não podem ser frustradas. $O$ ponto central da questão parece ser o valor vinculante de premissas universais formuladas nessas condições. 


\subsection{TRATANDO CASOS SEMELHANTES DA MESMA MANEIRA: OS ARGUMEN- TOS ANALÓGICOS NO DIREITO}

Até aqui, os esquemas apresentados têm como principal preocupação demonstrar as semelhanças entre um caso-alvo e um caso-fonte. Essa demonstração é vista como um passo importante para legitimar aquilo que se faz intuitivamente no dia a dia: confiar na validade de um princípio geral que é a base de todos os argumentos normativos por analogia, o princípio segundo o qual os casos semelhantes devem ser tratados igualmente (STEVENS, 2018, p. 4). Na Nova Retórica, Chaïm Perelman e Lucie Olbrechts-Tyteca chamam esse princípio geral de regra da justiça e tratam-na como base para um tipo especial de argumentação: a argumentação por reciprocidade (PERELMAN; OLBRECHTS-TYTECA, 1969, p. 221). Nesta subseção, a questão mais importante deixa de ser "o que são casos semelhantes?" e passa a ser "como casos semelhantes devem ser tratados?."

Nesse sentido, outra forte razão que Shecaira aduz para defender a existência de premissas universais (não-definitivas) que regem o argumento analógico a priori é o caráter institucional do direito. A articulação das premissas universais, os princípios subjacentes, é importante não só porque os juízes reconhecem que argumentos analógicos intuitivos são inferiores, mas também porque os juízes estão sujeitos a restrições institucionais, que exigem a tomada de decisões concretas que precisam levar em consideração normas gerais diretas, como atos normativos, ou indiretas, como outras decisões judiciais, relacionadas ao direito apresentado como base do argumento. Shecaira (2013, p. 435) conclui que os juízes, às vezes, abstêm-se de estabelecer premissas universais definitivas, porque sabem que, no futuro, outros juízes interpretarão suas decisões com base no princípio geral de que casos semelhantes devem ser tratados igualmente.

Voltando ao exemplo da Justiça do Trabalho, quando a decisão monocrática, cuja validade deveria ser confirmada ou refutada em grau de recurso, foi analisada pela $7^{\mathrm{a}}$ Turma do Nono Tribunal Regional do Trabalho (TRT9), o colegiado entendeu que:

Extrai-se da prova oral que a atividade principal desenvolvida pela Autora era contatar clientes, sempre por meio de ligações telefônicas, lançando o resultado das cobranças no sistema, sendo que esta atividade, por complementar ao teleatendimento (ativo e receptivo), não infirma a total predominância daquela.

Portanto, a rotina laboral da Obreira se encontra perfeitamente descrita no Anexo II da NR 17, pois, preponderantemente, comunicava-se com clientes, à distância, por intermédio de voz, com utilização de equipamentos de audição/ escuta e fala telefônica e sistemas informatizados de processamento de dados. Não se cogita, assim, de aplicação à Autora da duração laboral de 8 horas diárias e 44 semanais, pois o efetivo exercício de suas atribuições junto ao sistema de tele atendimento da Ré, enseja condição mais benéfica, decorrente da aplicação do art. 227 da CLT e do Anexo II da NR 17 do MTE. Frise-se que para a caracterização do direito à jornada especial é indiferente o ramo de atividade explorado pelo empregador, bem como o tipo de serviço prestado, pois a similitude se verifica no "modus operandi", a atrair a proteção legal. Assim, não 
havendo dúvidas de que a Reclamante desenvolveu atividades análogas às de teleatendimento [...]. (BRASIL, 2014, p. 21-22).

No acórdão, com mais clareza e detalhe do que no julgamento de primeira instância, o colegiado estabeleceu como características relevantes para o reconhecimento do direito à jornada reduzida: (i) a preponderância da comunicação por voz à distância, (ii) a utilização de equipamentos de escuta e fala telefônica e (iii) o uso de sistemas informatizados de processamento de dados.

A reconstrução desse argumento a partir do Esquema 3, que trata das semelhanças relevantes e estabelece uma premissa universal, poderia ser feita da seguinte forma: (Argumento 2)

1. A atividade de teleatendimento possui as características do ANEXO II da NR17.

2. A atividade da técnica administrativa do setor de cobrança da empresa de bebidas possui as características do ANEXO II da NR17.

3. A jornada de trabalho daqueles que exercem a atividade de teleatendimento é a prevista no art. 227 da CLT.

4. Em virtude do ANEXO II da NR 17, a jornada de trabalho de quem exerce a atividade de teleatendimento é aquela prevista no art. 227 da CLT.

5. A jornada de trabalho de qualquer atividade que possua as características do ANEXO II da NR 17 é aquela prevista no art. 227 da CLT.

Então,

6. A jornada de trabalho da técnica administrativa é aquela prevista no art. 227 da CLT (BRASIL, 1943).

$\mathrm{O}$ argumento analógico da $7^{\mathrm{a}}$ Turma do TRT9 parece padecer parcialmente dos problemas apontados por Govier. De fato, as premissas (1) e (3) são redundantes em função da premissa (4), explicitamente formulada. ${ }^{9}$ A premissa (5) poderia ser formulada posteriormente sob a alegação de estar implícita no acórdão, mas o fato de esse tipo de analogia estabelecer decisões sobre o que fazer ou dizer não permite deduzir que o que foi feito ou dito por um juiz em um caso específico deva ser feito por todos os juízes. As analogias falham como instrumento hábil para estabelecer premissas universais definitivas que possuem conteúdo, porque parecem exigir mais do que a certeza de que, no futuro, outros tomadores de decisão interpretarão a decisão com base no princípio geral de que casos semelhantes devem ser tratados igualmente; ela parece exigir a competência para legislar. ${ }^{10}$

9 Para ajudar a compreender esse ponto, Govier (1989, p. 144) usou esse esquema para explorar a ideia de que analogias com tal estrutura são argumentos implicitamente dedutivos em função da premissa 4 (em geral pressuposta) e de um passo relativamente curto e aparentemente natural, que estabelece uma declaração universal, a premissa 5. Ou seja, a analogia poderia ser conduzida a um nível de abstração em que a comparação seria desnecessária, por ser possível deduzir a conclusão a partir da premissa implícita (5), em um silogismo quase-lógico.

10 A $7^{\text {a }}$ Turma decidiu tratar a técnica administrativa como se fosse uma operadora de teleatendimento e usou como justificativa o ANEXO II da NR 17, que é uma forma categórica de tratar a atividade de teleatendimento. Contudo, um juiz, em um caso subsequente, poderia justificar sua decisão no mesmo sentido, recor- 
O resultado é diferente quando se afirma que uma premissa universal que independe de conteúdo não tem a pretensão de dizer qual deve ser a decisão. Nesse caso, fica mais claro que uma analogia serve para justificar o raciocínio paralelo desenvolvido no caso-alvo, para mostrar que a decisão no caso-alvo, assim como no caso-fonte, é a decisão correta. A reconstrução do acórdão a partir do Esquema 5 permitiria dizer que:

\section{(Argumento 3)}

1. É verdade que a jornada de trabalho de quem exerce a atividade de teleatendimento, cujo modus operandi é descrito no ANEXO II da NR 17, é aquela prevista no art. 227 da CLT.

2. A melhor razão para a crença nisso é que o que determina o direito à jornada especial não é o ramo de atividade explorado pelo empregador nem o tipo de serviço prestado, mas o modus operandi.

Então,

3. É verdade que o que determina o direito à jornada especial não é o ramo de atividade explorado pelo empregador, nem o tipo de serviço prestado, mas o modus operandi.

4. Se o que determina o direito à jornada especial é o modus operandi, então, a técnica administrativa tem direito à jornada de trabalho prevista no art. 227 da CLT (afinal, "C implica b").

Logo,

5. É verdade que a técnica administrativa tem direito à jornada de trabalho prevista no art. 227 da CLT (BRASIL, 1943).

Talvez Waller (2001) e Shecaira (2013) não comunguem com a crítica de Govier porque tinham em mente que são as premissas universais que independem de conteúdo as responsáveis por regerem as analogias e fazerem perceber as semelhanças. Esse é o tipo de premissa que torna a analogia útil em função da orientação que elas parecem oferecer, das lições que parecem ensinar ou da persuasão que parecem exercer. $\mathrm{O}$ esquema de Govier, ao contrário, parece induzir a realização de um raciocínio categórico e prescritivo, que exige competência para legislar, mais do que a certeza de que, no futuro, outros tomadores de decisão poderão interpretar a decisão com base no princípio geral de que casos semelhantes devem ser tratados igualmente (princípio geral de justiça).

É por isso que Stevens (2018, p. 11-12, nota 7) entende que o princípio geral de justiça é central na discussão sobre a distinção entre analogias e precedentes. Avaliar argumentos caso a caso é um desafio, porque a estrutura do argumento não marca a diferença essencial; o mais importante está implícito, a saber, o tipo de raciocínio envolvido na formulação. Fica claro que o argumento analógico, diferentemente do argumento por precedente, é um raciocínio que procura paralelismos entre os casos. ${ }^{11}$ Se a pretensão é

rendo apenas à afirmação de que a $7^{\text {a }}$ Turma estabeleceu que a jornada de trabalho de qualquer atividade que possua as características do ANEXO II da NR 17 é aquela prevista no art. 227 da CLT?

11 Stevens escolhe esse termo para indicar que, em verdade, o raciocínio analógico tem um aspecto meta-argumentativo. Sobre os exemplos e a conclusão pela diferença em função dos raciocínios e não dos argumentos, ver Stevens (2018, p. 1-2). 
estabelecer uma premissa universal definitiva que possui conteúdo, o precedente é o meio mais adequado.

Stevens (2018, p. 22) defende que o princípio geral de justiça possui duas versões que guiam diferentes tipos de raciocínio caso a caso. Há um tipo de argumento caso a caso que apela a um raciocínio paralelo que pressupõe que a decisão passada estava justificada e que, em razão disso, uma decisão presente equivalente também estaria justificada. Há, ainda, o argumento por precedente, que cita a existência da decisão passada como motivo para decidir novamente no mesmo sentido, independentemente dos méritos da decisão passada. A autora destaca que a aparência semelhante dos dois tipos de argumentos representa um potencial risco de uso falacioso, pela dificuldade de avaliar os argumentos.

Raciocínios que procuram paralelismos e produzem argumentos analógicos usam a versão fraca do princípio, a qual não garante que a existência de uma decisão anterior semelhante seja, por si só, razão suficiente para a justificativa de um tratamento igualitário. Essa conclusão só poderá ser garantida se for possível afirmar que a decisão no caso-fonte está correta ou justificada (STEVENS, 2018, p. 4). A cada analogia, seria preciso entrar no mérito da questão, procurando a melhor decisão possível.

Ao pensar a analogia como um meta-argumento que justifica tomar uma decisão no mesmo sentido, Stevens chega ao seguinte esquema de argumentação: ${ }^{12}$

(Esquema 6)

1. A consideração de todas as circunstâncias, o caso C1 é similar ao caso C2.

2. A decisão A foi tomada em C1.

3. A decisão A estava justificada em C1.

Logo,

4. A decisão A deve ser tomada em C2.

Ela formula ainda um conjunto de perguntas que são críticas para distinguir um argumento analógico (STEVENS, 2018, p. 18):

(P1) Como a decisão foi justificada em C1?

(P2) Os dois casos são suficientemente semelhantes em relação às características que justificaram a decisão em C1?

(P3) Quais as diferenças relevantes entre C1 e C2?

(P4) Existem fontes alternativas de casos análogos que poderiam servir para a construção de argumentos com conclusões incompatíveis?

A reconstrução do acórdão do TRT9, de acordo com esse esquema, poderia ser feita da seguinte forma:

(Argumento 4)

1. A consideração de todas as circunstâncias, a atividade de técnica administrativa no setor de cobrança é similar à atividade de teleatendimento.

12 O caráter de meta-argumento seria uma consequência da pretensão do segundo argumento ser convincente em razão do primeiro ter sido. 
2. A decisão de equiparar a jornada de trabalho de atividades análogas à atividade de teleatendimento foi tomada anteriormente. ${ }^{13}$

3. A decisão pela equiparação estava justificada nos casos anteriores.

Logo,

4. A decisão de equiparar a atividade de técnica administrativa no setor de cobrança é similar à atividade de teleatendimento e deve ser tomada em sede de recurso.

Seria possível responder às perguntas de Stevens da seguinte forma:

(R1) As decisões anteriores estavam justificadas por ser indiferente o ramo de atividade explorado pelo empregador, bem como o tipo de serviço prestado, uma vez que a similitude da atividade deve ser verificada no modus operandi, atraindo a proteção legal.

(R2) Os casos são semelhantes porque, em todos eles, as atividades efetivamente exercidas eram análogas à atividade de teleatendimento, embora nominalmente fossem atividades de outro tipo (recuperador de crédito, operador de cobrança, vendedor).

(R3) Os julgados citados não apontaram diferenças relevantes.

(R4) Os casos em sentido diverso seriam contrários à aplicação analógica do art. 227 da CLT, da Súmula no 178 do TST e do item 5.3 do Anexo II da NR 17.

O interessante na proposta de Stevens (2018) é a complementariedade entre um esquema argumentativo formal, que está preocupado em deixar explícitas as razões efetivamente dadas para justificar a analogia, e um conjunto de perguntas críticas que ajudam a identificar o contexto a partir do qual a analogia foi realizada. Seu esquema parece representar melhor a forma de argumentação jurídica real, porque a proposta de Shecaira (2013) é mais sofisticada e está mais distante da forma como as decisões são justificadas. Buscar os princípios de acordo com esse esquema envolve trabalhar com um argumento complexo e composto por duas inferências: uma não dedutiva, que estabelece um acordo sobre premissa universal, e outra dedutiva que, a partir da premissa universal acordada, leva a uma conclusão necessária. Isso torna a avaliação dos argumentos mais difícil.

\section{QUAL É A LÓGICA DO ARGUMENTO POR PRECEDENTE?}

Waldron (2012, p. 4) defende a existência de um subconjunto de razões que justificam a doutrina do precedente para os juristas da common law, relacionadas ao Estado de Direito (Rule of Law). A generalidade é uma dessas razões, quando entendida como uma restrição à tomada de decisão no caso precedente e ao seu impacto sobre o tratamento de casos semelhantes (WALDRON, 2012, p. 9). O autor justifica sua visão recorrendo ao caso Planned Parenthood v. Casey, ${ }^{14}$ em que a Suprema Corte do Estados Unidos citou o Estado de Direito

13 Na relatoria, foram citados vários julgados anteriores que decidiram pela equiparação, como Recursos de Revista (RR) $\mathrm{n}^{\mathrm{o}}$ 399-34.2012.5.03.0023, 105900-27.2005.5.01.0039, 96300-34.2005.5.04.0027, 19270077.2008.5.02.0022, 123100-96.2008.5.01.0021 e 49100-19.2005.5.07.0004 e Agravos de Instrumento ao $\mathrm{RR}^{\mathrm{o}}$ 2151540-65.2006.5.09.0005, 33100-24.2006.5.02.0011 e 1366-60.2010.5.05.0034. Eles fazem parte do argumento e entram nessa premissa, ver Brasil (2014).

14 Ver Planned Parenthood of Southeastern Pa. v. Casey, 505 U.S. 833 (UNITED STATES OF AMERICA 1992). 
como motivo para não reverter (superar) os precedentes com muita frequência. Ela precisava decidir se reverteria a decisão do caso Roe v. Wade, ${ }^{15}$ então, dedicou uma longa seção à questão da doutrina do precedente. A Corte insistiu que o próprio conceito de Estado de Direito requer uma continuidade ao longo do tempo, sendo o respeito ao precedente, por definição, indispensável (WALDRON, 2012, p. 5).

Contudo, Waldron (2012, p. 10) alertou que, antes de tentar fundamentar a doutrina do precedente como uma implicação necessária do princípio geral de justiça, era preciso estabelecer quais expectativas serão protegidas pelo direito como legítimas. Para o autor, a doutrina do precedente só se justifica se dois elementos indispensáveis do princípio da proteção das expectativas ${ }^{16}$ estiverem presentes. Primeiro, o precedente precisa ser uma prática jurídica ou modelo de processo decisório capaz de proporcionar expectativas. Segundo, as expectativas geradas pelo precedente devem, em geral, ser respeitadas pelos demais tomadores de decisão. O processo decisório de repercussão geral seria um bom exemplo de processo decisório apto a gerar expectativas e a torná-las exigíveis dos tomadores de decisão.

Os dois elementos suscitam uma importante questão: as expectativas fluem em dois sentidos, elas descem e sobem. Nessa linha, como fortalecer o respeito das instâncias inferiores às superiores? Waldron diz que é preciso separar duas ideias diferentes, porém conexas: a justificativa para seguir o que foi decidido em um caso anterior não é autoevidente, tendo em vista que o processo decisório deve estabelecer formas de dizer porque uma decisão é um precedente ou que a prática jurídica deve preencher essa lacuna de forma clara. Uma vez que os dois elementos estejam presentes, existirão razões as quais justificam considerar uma decisão judicial como um precedente, razões de segunda ordem, ${ }^{17}$ de maneira que haverá um status normativo demandando cautela, antes de superar, substituir ou derrubar uma decisão que é reconhecida como um precedente (WALDRON, 2012, p. 5).

\subsection{TRATANDO CASOS SEMELHANTES (COERCITIVAMENTE) DA MESMA FOR- MA: O USO DE PRECEDENTES NO DIREITO}

Como visto, o raciocínio que procura paralelismos e produz um argumento analógico precisa olhar as características relevantes e a justificativa do caso-fonte para demonstrar que, em função delas, o tratamento igualitário é necessário ou está justificado para o caso-alvo. O raciocínio é paralelo porque o tomador de decisão não pode se livrar do

15 Ver Roe v. Wade, 410 U.S. 113 (UNITED STATES OF AMERICA, 1973).

16 Como a ideia de promover a previsibilidade por meio do precedente é uma ideia complicada, Waldron (2012, p. 10) entende que juristas invocam o princípio da proteção das expectativas para justificar a necessidade de decidir conforme um precedente.

17 Uma das descobertas filosóficas mais importantes de Joseph Raz foi perceber que o estabelecimento do equilíbrio entre razões de primeira ordem, de modo a determinar como agir, não é a única forma de raciocínio prático em que as pessoas confiam. Às vezes, decide-se como agir com base no que Raz chama de razões de segunda ordem, algo que ele define como uma "razão para agir ou não agir de acordo com uma razão" (PERRY, 1989, p. 913). 
ônus da justificação simplesmente invocando a decisão anterior como uma regra para decidir o caso atual. $\mathrm{O}$ princípio geral de justiça tem validade universal e serve às analogias e aos precedentes.

Voltando ao caso da técnica administrativa (Argumento 1), julgado pelo TRT9, a existência de uma decisão judicial anterior dizendo que quem cumpre a função de operador de serviço de telefonia deve, de acordo com o art. 227 da CLT (BRASIL, 1943), ter carga horária reduzida não desonera o autor da analogia do ônus de apresentar suas razões para considerar a técnica administrativa como telefonista. $\mathrm{O}$ autor da analogia teria de enfrentar as objeções apresentadas para tratar os casos de forma semelhante.

No entanto, esse princípio nem sempre é usado no sentido fraco, muitas vezes, ele é invocado para legitimar que o fato de um caso ter sido decidido no sentido A no passado é, por si só, razão para decidir no mesmo sentido em casos semelhantes. Quando o direito faz menção expressa ao princípio, é provavelmente a essa versão forte que ele faz referência. Como Stevens (2018, p. 5) ressalta, embora esse princípio seja um dos que justifica a doutrina do precedente vinculante, ele não tem força justificatória independente. ${ }^{18}$ Se assim fosse, haveria um movimento indiscriminado no sentido de atribuir status normativo a qualquer decisão ou enunciado, ou seja, tudo seria um precedente. Em razão disso, Stevens (2018, p. 6) defende que a versão forte do princípio geral não se sustenta sem a presença de uma razão de segunda ordem.

Por exemplo, para ajudar a decidir, quando reafirmar um precedente em matéria constitucional, os Justices do caso Planned Parenthood $v$. Casey ${ }^{19}$ investigaram e destacaram quatro práticas do Tribunal que serviriam como razões de segunda ordem: (i) se a regra constitucional provou ser impraticável, emerge um precedente; (ii) se a sociedade construiu um considerável nível de confiança nos termos de uma decisão, essa decisão é um precedente; (iii) se as doutrinas jurídicas mudaram tanto que uma regra se tornou obsoleta, um precedente se forma; e, (iv) se os fatos mudaram tanto que uma regra se tornou insignificante ou "letra morta", exsurge um precedente. $\mathrm{O}$ incidente de resolução de demandas repetitivas e o sistema de recursos extraordinário e especial repetitivos são exemplos de razões de segunda ordem no sistema jurídico brasileiro. Por meio deles, busca-se otimizar a resolução de casos semelhantes, partindo da premissa de que suas teses firmadas dão origem a "precedentes" (MARINONI, 2016, p. 45-46). ${ }^{20}$

18 Ver também Waldron (2012, partes III e IV).

19 Ver Planned Parenthood of Southeastern Pa. v. Casey, 505 U.S. 833 (UNITED STATES OF AMERICA, 1992).

20 É importante destacar que, apesar de Marinoni criticar os termos estabelecidos pelo CPC/2015 para a resolução do incidente de recursos repetitivos por violar o direito constitucional de participar em contraditório, ele reconhece que o incidente de resolução de demandas repetitivas se destina a regular casos que já surgiram ou que podem surgir em face de determinado litígio. Ao oferecer uma alternativa processual que permite a correção da inconstitucionalidade, dando ampla participação no incidente aos interessados, Marinoni parece reforçar que não se pode ignorar a repercussão que esse tipo de incidente exerce sobre o raciocínio que dá origem à decisão judicial, ou seja, enquanto houver razão suficiente para decidir novamente da maneira A em casos semelhantes, o incidente pode ser considerado um precedente. 
Analisando a questão sob outro ângulo, Macêdo (2015, p. 464) defende que "os precedentes são uma forma de garantir limites à atividade criativa dos juízes, e não de reforçar a criatividade ou dar mais poderes." Para ele, existe uma clara preocupação com a definição de limites para a criação de direito jurisprudencial, de maneira que o respeito aos precedentes vinculantes assumiria como premissas o fato de que juízes podem criar normas, assim como a expectativa de que eles estarão limitados no seu processo criativo por normas que regulam essa criação (MACÊDO, 2015, p. 464).

É difícil negar que o argumento por precedente opera de maneira diversa do argumento analógico, mesmo que se jogue com o precedente a ponto de estabelecer uma construção que funcione tanto como uma regra quanto como uma analogia (MAUÉS, 2012, p. 597-603), porque a versão forte do princípio geral de justiça não tem força independente (STEVENS, 2018, p. 7). Quem raciocina por precedentes precisa, ao se deparar com o caso atual, verificar se existe alguma decisão anterior exigivel sob determinadas circunstâncias (STEVENS, 2018, p. 6). Esse é o status de autoridade, como destaca Schauer (2009). Não se trata de escolher o precedente que permite alcançar a melhor decisão possível, e sim de estar obrigado a iniciar o raciocínio jurídico a partir de uma premissa universal estabelecida em um caso anterior, simplesmente porque essa decisão anterior existe (SCHAUER, 2008, p. 9).

Porém, como saber quando é esse o caso? Stevens $(2018$, p. 18) propõe o seguinte esquema:

(Esquema 7)

1. A consideração de todas as circunstâncias, o caso $\mathrm{C} 1$ é semelhante ao caso C2.

2. A decisão $\mathrm{A}$ foi tomada em $\mathrm{C} 1$.

3. Existe uma justificativa para tratar a existência da decisão $A$ em $\mathrm{C} 1$ como uma razão para

decidir A em casos semelhantes.

Logo,

4. A decisão A deve ser tomada em C2.

Stevens (2018, p. 20-21) justifica a diferença entre o status de autoridade do precedente (premissa 3 desse esquema) e a sabedoria da analogia (premissa 3 do Esquema 6), fazendo um raciocínio paralelo ao feito para distinguir a autoridade prática e teórica no direito.

Um precedente pretende prescrever como decidir casos futuros, ao passo que a analogia pretende fazer constatações factuais sobre como o caso foi decidido. Um precedente é invocado para afirmar uma capacidade de promover previsibilidade, estabilidade e coordenação, capacidades necessárias à implementação de regras e políticas públicas, ao passo que é natural ser deferente a uma analogia, quando o tomador de decisão imagina que seu antecessor estava mais bem aparelhado para descobrir a verdade dos fatos relevantes, ou estava, mesmo que transitoriamente, em melhor posição do que ele próprio para estabelecer a verdade dos fatos em questão. 
O uso de um precedente se fundamenta no seu status, mas é a especialização da decisão, entendida como maior probabilidade de acesso à verdade em função das circunstâncias, que normalmente figura entre os fundamentos que buscam justificar o uso da analogia. ${ }^{21}$

Uma questão que pode parecer problemática a esta altura diz respeito à concepção de analogia mais familiar ao direito brasileiro, qual seja, ser um raciocínio voltado a suprir uma lacuna da lei, mais do que ser um raciocínio voltado a fornecer uma razão para crer que algo é verdadeiro. Não se ignora essa distinção, mas acredita-se que essas duas concepções sejam complementares. Primeiro, porque, quando uma analogia supre uma lacuna da lei, ela o faz no caso concreto, como norma individual sem capacidade de determinar como outro juiz deve se comportar, dentro de um espectro de ações possíveis, ou seja, sem caráter normativo nesse sentido.

Segundo, a capacidade de influenciar outro juiz é consequência da deferência fundada em uma de duas possibilidades; ou se imagina que o autor da analogia estava, mesmo que transitoriamente, em uma posição melhor para estabelecer a verdade (SHECAIRA, 2017, p. 308-309), ou se considera que a opinião do autor da analogia é sólida porque suas opiniões são susceptíveis de serem superiores às demais em razão da maior probabilidade de identificar a solução que alcance, nos casos de incerteza, o melhor equilíbrio entre valores concorrentes (LAMOND, 2010, p. 18-19). Ambas as possibilidades são formas de justificar a existência de uma autoridade teórica que emite declarações factuais e não prescrições.

Lopes Filho (2012, p. 245-246) torna sua concepção de precedente mais fraca e próxima da analogia, talvez retomando a ideia de precedente persuasivo, quando afirma que a "força hermenêutica do precedente se traduz, portanto, em uma força variável em função do jogo de-e-para próprio do círculo hermenêutico que determina o grau de influência de um precedente para o novo caso." O precedente vinculante não exerce pouca influência, ou o precedente incide no caso, ou o caso deve ser distinguido para se livrar da norma do precedente. Quando esse é o caso, sua resolução pode se dar por recurso à analogia ou à outra técnica jurídica. Quem possui uma força variável de aplicação, mensurável por meio de uma lógica dialética é o caso-fonte da analogia, é no seu interior que se estabelece uma analogia de fato ou de direito como defende Lopes Filho. A analogia é um exemplo típico da análise ampla do todo hermenêutico, análise que inevitavelmente fica mitigada quando se trata de aplicar um precedente.

21 Sobre a distinção entre os dois tipos de autoridade no direito, ver Shecaira (2017) e Lamond (2010). Shecaira critica Lamond, defendendo uma distinção fraca entre os tipos de autoridade (distinção utilizada neste artigo). Lamond traz importantes considerações sobre a relação entre tipos de autoridade e tipos de fonte no direito. Ele relaciona a autoridade prática às fontes obrigatórias do direito e a autoridade teórica às fontes persuasivas. Para executar o raciocínio paralelo proposto, é importante ter em mente que ter autoridade prática sobre o outro, no sentido que importa à presente investigação, é ter o poder (normativo), enquanto membro do Poder Judiciário, de decidir como outro magistrado deve se comportar, dentro de um espectro de ações possíveis, ao passo que ter autoridade teórica é possuir a capacidade de influenciar outro juiz. 
Complementarmente ao esquema, Stevens (2018, p. 18) propõe outro conjunto de perguntas críticas, de maneira similar às perguntas críticas sobre analogias, para avaliar um argumento por precedente:

(P1) Qual a justificativa para tratar a existência da decisão no C1 como razão para decidir C2?

(P2) Os dois casos são suficientemente relevantes em relação às características de C1?

(P3) Existem diferenças relevantes entre $\mathrm{C} 1$ e C2?

(P4) Existem outros casos semelhantes que possam levar a conclusão diferente e incompatível?

O que parece ser a principal diferença entre os dois conjuntos de perguntas críticas é a busca pela razão de segunda ordem, que justifica o uso de precedentes. $O$ conjunto de perguntas sobre precedente parece subvalorizar as diferenças entre os casos. A consequência de encontrar uma diferença relevante na analogia não obriga o autor a superar nenhum tipo de ônus, apenas o faz sair a busca de outra fonte. Em contraponto, a consequência de encontrar uma diferença relevante entre casos que supostamente estão sob incidência de um precedente conduz o tomador de decisão à tarefa de superar o ônus da distinção ${ }^{22}$ dos casos, um ônus similar ao de "derrotar" uma regra.

Parece haver uma importante pergunta a ser feita quando a resposta à P3 é positiva: havendo uma diferença relevante, ela é suficiente para justificar o afastamento do precedente?

Usar outro exemplo da Justiça do Trabalho pode ajudar a compreender melhor essa versão forte do princípio geral de justiça, em função de uma razão de segunda ordem.

Em sede de Recurso de Revista (RR), o Tribunal Superior do Trabalho (TST) acolheu a pretensão do empregador para rever a decisão do Tribunal Regional do Trabalho da $4^{\mathrm{a}}$ Região (TRT4). A decisão de segunda instância considerou a atividade de suporte técnico remoto (por telefone) análoga à atividade de teleatendimento, sendo, portanto, insalubre, conforme Súmula $66^{23}$ do próprio TRT4. A decisão foi revisada pelo TST, entre outras razões, por estar em desacordo com a tese jurídica reafirmada no julgamento do Incidente de Recursos de Revistas Repetitivos [IRRR] no TST-IRR-356-84.2013.5.04.0007 pela SDI-1 da Corte, em 25/5/2017, com efeito vinculante, nos moldes do art. 896-C, § 11, da CLT (BRASIL, 2017).

À referida decisão, a reclamada, [...] interpôs o presente recurso de revista [...], tendo em vista que as atividades exercidas pela reclamante não se enquadram na classificação contida no Anexo 13 da NR-15 (fls. 290/296 seq. $\left.\mathrm{n}^{\circ} 1\right)$. [...]. Interpretando o mencionado dispositivo, a jurisprudência deste Tribunal Superior consolidou-se no sentido de que, para efeito de percepção do adicional de insalubridade, revela-se imprescindível a classificação da atividade insalubre na relação oficial elaborada pelo Ministério do Trabalho, não bastando a constatação por laudo pericial, conforme se depreende do item I da Súmula $n^{\circ} 448$. [...]. A referida diretriz foi reafir-

22 A distinção (distinguishing) é uma técnica prevista na doutrina do precedente para excluir um caso específico do âmbito de incidência de uma regra formulada no precedente.

23 Súmula no 66 - ADICIONAL DE INSALUBRIDADE. UTILIZAÇÃO DE FONES DE OUVIDO. A atividade com utilização constante de fones de ouvido, tal como a de operador de teleatendimento, é passível de enquadramento no Anexo 13 da NR 15 da Portaria no 3.214/78 do Ministério do Trabalho e Emprego (BRASIL, 2015). 
mada no julgamento do Incidente de Recursos de Revistas Repetitivos $\mathrm{n}^{\mathrm{o}}$ TST-IRR-356-84.2013.5.04.0007 pela SDI-1 desta Corte, em 25/5/2017, com efeito vinculante, nos moldes do art. 896-C, § 11, da CLT, no qual se fixou a seguinte tese jurídica: ' 1 . O reconhecimento da insalubridade, para fins do percebimento do adicional previsto no artigo 192 da CLT, não prescinde do enquadramento da atividade ou operação na relação elaborada pelo Ministério do Trabalho ou da constatação de extrapolação de níveis de tolerância fixados para agente nocivo expressamente arrolado no quadro oficial. 2. A atividade com utilização constante de fones de ouvido, tal como a de operador de telemarketing, não gera direito ao adicional de insalubridade, tão somente por equiparação aos serviços de telegrafia e radiotelegrafia, manipulação em aparelhos do tipo Morse e recepção de sinais em fones, para os fins do Anexo 13 da Norma Regulamentadora 15 da Portaria no 3.214/78 do Ministério do Trabalho.'

Nesse contexto, considerando que a atividade desenvolvida pela reclamante, operadora de telemarketing, não está enquadrada entre aquelas descritas no referido Anexo 13 da NR-15, é incabível o deferimento do adicional de insalubridad. (BRASIL, 2017, online).

O esquema argumentativo seria, então, o seguinte:

\section{(Argumento 5)}

1. A consideração de todas as circunstâncias, o caso do IRRR é semelhante ao caso do RR.

2. A decisão de que a atividade com utilização constante de fones de ouvido, tal como a de operador de telemarketing, não gera direito ao adicional de insalubridade foi tomada no IRRR.

3. Existe uma justificativa para tratar a existência da decisão no IRRR como razão para decidir casos semelhantes da mesma forma.

Logo,

4. A decisão de não reconhecimento de insalubridade deve ser tomada no RR.

Seria possível responder às perguntas críticas da seguinte forma:

(R1) Segundo a Lei $n^{0} 13.105 / 2014$, se o TST, ao receber um RR, considerar que a matéria é repetitiva, todos os recursos que estiverem nos TRTs sobre o mesmo tema ficarão sobrestados aguardando a decisão do recurso paradigma ou leading case. Decidido o paradigma, todos os demais deverão ser julgados no mesmo sentido.

(R2) Os dois casos são semelhantes, porque a existência de um laudo pericial não supre a falta de regulamentação do Ministério do Trabalho e Emprego.

(R3) Não existem diferenças relevantes que justifiquem distinção em relação ao precedente.

(R4) Embora exista a Súmula 66 do TRT4, seu enunciado não é vinculante como a decisão do TST em IRRR.

Destaque-se a decisão do TST também ter argumentado analogicamente. O julgado elencou uma série de decisões do próprio Tribunal, chamadas pelo relator de "precedentes", que comprovavam a manutenção de um raciocínio paralelo ao longo do tempo, embora o uso dessa série histórica tivesse a pretensão de demonstrar a 
existência de entendimento prevalecente no TST, uma quase obrigação a fundamentar a formalização da tese em IRRR. Em uma das citações da decisão, a Min. Delaíde Miranda Arantes declarou:

1 - Entendimento pessoal desta relatora no sentido do enquadramento da função de telefonista no Anexo 13 da Norma Regulamentadora 15 da Portaria 3.214/778 do Ministério do Trabalho, por analogia à proteção dispensada aos operadores de telegrafia e radiotelegrafia. 2 - Todavia, em homenagem ao caráter uniformizador da jurisprudência do TST, é necessário curvar-me ao posicionamento iterativo desta Corte, segundo o qual, a função de telefonista, por não estar classificada como atividade insalubre pelo Ministério do Trabalho, não enseja o pagamento de adicional de insalubridade (BRASIL, 2017, online).

Parece existir uma transição natural do pioneirismo de uma analogia à criação do direito pelo precedente, o que se poderia chamar de normalização do raciocínio paralelo. Uma analogia costumeira dificilmente seria contestada no âmbito do controle judicial, mas isso não desnatura sua natureza de analogia, pois lhe falta a razão de segunda ordem característica do precedente, ou seja, o tomador de decisão continua tendo de demonstrar os méritos da sua decisão, em vez de apenas indicar que a sua decisão acompanha uma decisão anterior. A existência da tese em IRRR bastaria, por si só, para justificar a revisão judicial do RR e excluir a condenação pelo TRT4 ao pagamento de adicional de insalubridade.

A decisão do TST poderia ter sido mais objetiva. Ao aplicar um precedente, a questão não é saber "o quanto" de "precedentes" é preciso ter para justificar a decisão, mas "o que" é um precedente que justifica, por si só, a decisão.

\section{CONCLUSÃO}

Dentro da proposta de destacar as diferenças entre o esquema argumentativo que apela ao precedente e o esquema argumentativo que recorre à analogia, que são dois tipos distintos de tomada de decisão caso a caso, foram apresentadas, em primeiro lugar, propostas as quais tentaram sofisticar a analogia, tornando-a menos intuitiva, mais consistente e prospectiva. Essas tentativas tenderam a aproximar o resultado da analogia de uma regra e, consequentemente, da visão mais generalizada que se tem de um precedente. Ao analisar o papel da analogia no ambiente fortemente institucionalizado do direito, foi possível constatar que, apesar de parecer ter um efeito prospectivo, há objeções relevantes quanto a essa capacidade, em razão da própria natureza do raciocínio analógico, que concede, inevitavelmente, liberdade para estabelecer quais são as semelhanças relevantes entre casos.

Apelar para precedentes é significativamente diferente. Em que sentido? A presença de razões de segunda ordem determina o ponto de partida do raciocínio jurídico do tomador de decisão, marcando essa deliberação por precedentes, ao mesmo tempo que a diferencia da tomada de decisão por analogia. A ideia de que princípio geral de acordo com o qual 
casos semelhantes devam ser tratados igualmente (aqui chamado de princípio geral de justiça) justifica, por si só, o uso de precedentes é enganosa, porque esse princípio, atuando isoladamente, não consegue ser seletivo o suficiente para determinar quais decisões são vinculantes ou não.

Nesse sentido, a proposta de Katharina Stevens se mostra interessante e inovadora, porque consegue conciliar a análise lógica do argumento, sua estrutura de proposições que conduzem a uma conclusão, à verificação das circunstâncias ou intenções do autor - o aspecto retórico da argumentação. Conjugar esquemas abstratos e um conjunto de perguntas críticas se mostra uma estratégia eficaz, em razão do fácil manuseio e da grande utilidade, na reconstrução dos argumentos reais dos tribunais e na avaliação da intenção implícita na decisão: estabelecer uma analogia ou aplicar um precedente. A proposta de Stevens ajuda a manter em mente a importante distinção entre os dois tipos de argumentação caso a caso, e isso pode evitar a atribuição de efeitos equivocados às decisões anteriores. Em suma, apresenta-se uma estratégia argumentativa para o processo decisório que auxilia a identificar um "precedente", legitimando o recurso a seu efeito vinculante.

\section{REFERÊNCIAS}

BRASIL. Decreto-Lei n. ${ }^{0}$ 5.452, de $1^{\circ}$ de maio de 1943. Aprova a Consolidação das Leis do Trabalho. Presidência da República, Brasília, 1943. Disponível em: <http://www. planalto.gov.br/ccivil_03/decreto-lei/Del5452.htm >. Acesso em: 21 jan. 2018.

. Tribunal Regional do Trabalho (9. Região). Recurso Ordinário. Recte.: Wipro do Brasil Tecnologia Ltda. Recdo.: Suelen Manosso de Lima. Rel.: Des. ${ }^{\circ}$ Ubirajara Carlos Mendes. Curitiba, PR, 19 de setembro de 2014. Disponível em: <https://www.trt9. jus.br/portal/arquivos/4191644>. Acesso em: 20 jan. 2018.

. Tribunal Regional do Trabalho (4. Região). Súmula no 66. Adicional de insalubridade. Utilização de fones de ouvido. Resolução Administrativa n ${ }^{\circ}$ 18/2015 Disponibilizada no DEJT dias 02, 03 e 05 de junho de 2015, considerada publicada dias 03, 05 e 08 de junho de 2015. In:___. Súmulas. Rio Grande do Sul, 2015. Disponível em: <https://www.trt4.jus.br/portais/trt4/sumulas>. Acesso em: 2 fev. 2018.

. Tribunal Superior do Trabalho. Recurso de Revista. Recte.: Totvs S.A. Recdo.: Douglas de Freitas. Rel.: Min. Dora Maria da Costa. Brasília, DF, 21 jun. 2017. Disponível em: <http://aplicacao5.tst.jus.br/consultaunificada2/inteiroTeor.do?action $=$ printInteiroTeor $\&$ format $=h t m l \&$ highlight $=$ true\&numeroFormatado $=R R \% 20-\% 20$ 20977-65.2014.5.04.0008\&base $=$ acordao $\&$ rowid $=$ AAANGhAA + AAATiWAAH\&da taPublicacao $=23 / 06 / 2017$ \&localPublicacao $=$ DEJT\&query $>$. Acesso em: 21 jan. 2018.

GOVIER, Trudy. A practical study of argument. 7. ed. [S.1.]: Cengage Learning, 2013. 
. Analogies and missing premises. Informal Logic, v. 11, n. 3, p. 141-152, 1989.

. Should a priori analogies be regarded as deductive arguments? Informal Logic, v. 22, n. 2, p. 155-157, 2002.

LAMOND, Grant. Precedent and analogy in legal reasoning. Stanford Encyclopedia of Philosophy, 2016. Disponível em: < https://stanford.library.sydney.edu.au/entries/legalreas-prec/>. Acesso em: 13 jan. 2018.

. Persuasive authority in the law. The Harvard Review of Philosophy, v. 17, n. 1, p. 16-35, 2010.

LOPES FILHO, Juraci Mourão. Precedente e norma: usam-se precedentes judiciais como se aplicam normas legislativas? Revista Opinião Jurídica, Fortaleza, v. 10, n. 14, p. 231 252, 2012.

MACÊDO, Lucas Buril. A disciplina dos precedentes judiciais no direito brasileiro: do anteprojeto ao Código de Processo Civil. In: DIDIER JR., Fredie et al. (Coords.). Precedentes. Salvador: Juspodivm, 2015. p. 459-490.

MARINONI, Luiz Guilherme. A ética dos precedentes: justificativa do novo CPC. 2. ed. São Paulo: Revista dos Tribunais, 2016.

MAUÉS, Antonio Gomes Moreira. Jogando com os precedentes: regras, analogias, princípios. Revista Direito GV, v. 8, n. 2, p. 587, 2012.

PERELMAN, Chaim; OLBRECHTS-TYTECA, Lucie. The New Rhetoric: a treatise on argumentation. Notre Dame: University of Notre Dame, 1969.

PERRY, Stephen R. Second-order reasons, uncertainty and legal theory. Southern California Law Review, v. 62, p. 913-994, 1989.

SCHAUER, Frederick. Why precedent in law (and elsewhere) is not totally (or even substantially) about analogy. Perspectives on Psychological Science, v. 3, n. 6, p. 1-27, 2008.

. Thinking Like a Lawyer: a new introduction to legal reasoning. Cambridge: Harvard University Press, 2009.

SHECAIRA, Fábio Perin. Analogical arguments in ethics and law: a defence of a deductivist analysis. Informal Logic, v. 33, n. 3, p. 406-437, 2013.

. Legal arguments from scholarly authority. Ratio Juris, v. 30, n. 3, p. 305-321, 2017.

STEVENS, Katharina. Case-to-Case Arguments. Argumentation, p. 1-25, 2018.

UNITED STATES OF AMERICA. Planned Parenthood of Southeastern Pa. v. Casey, 505 U.S. 833 (1992). 1992. Disponível em: < https://supreme.justia.com/cases/federal/ us/505/833/>. Acesso em: 2 fev. 2018. 
. Roe v. Wade, 410 U.S. 113 (1973). Disponível em: <https://supreme.justia.com/ cases/federal/us/410/113/case.html>. Acesso em: 2 fev. 2018.

WALDRON, Jeremy. Stare decisis and the rule of law: a layered approach. Michigan Law Review, v. 111, p. 1-32, 2012.

WALLER, Bruce N. Classifying and analyzing analogies. Informal Logic, v. 21, n. 3, p. 199-218, 2001. 